\title{
Simulated stability tests of a small articulated tractor designed for extreme-sloped vineyards
}

\author{
F. Mazzetto, ${ }^{1}$ M. Bietresato, ${ }^{1}$ A. Gasparetto, ${ }^{2}$ R. Vidoni ${ }^{1}$ \\ ${ }^{1}$ Free University of Bozen-Bolzano, Faculty of Science and Technology, Fa.S.T., Bolzano, Italy; \\ ${ }^{2}$ Università degli Studi di Udine, Dipartimento di Ingegneria Elettrica, Gestionale e Meccanica, \\ DIEGM, Udine, Italy
}

\begin{abstract}
A new reversible wheeled articulated tractor, designed to work in terraced vineyards trained with "pergola" system, common in mountain areas, is here described in its latest version and analysed through numerical simulations.

This tractor has small dimensions, necessary to operate in that environment, and its central articulation has two rotational degrees-offreedom. The described features are surely strong design points but could be critical for vehicle's stability, as affecting the supporting base's dimensions and shape. Therefore, the tractor was equipped with a new automatic safety system: a self-locking articulation activated by contact sensors on the wheels. This device makes the vehicle partially-rigid in case of lateral unbalancing, so that rollover can happen only by overcoming the whole vehicle mass.

A mathematical description of vehicle-ground interactions was implemented to deeply inquiry the tractor behaviour in different configurations (straight, angled) at increasing values of ground slope; roll and pitch stability indexes were then computed and used for comparisons with conventional tractors.
\end{abstract}

Correspondence: Marco Bietresato, Free University of Bozen-Bolzano, Faculty of Science and Technology, Fa.S.T., piazza Università 5, P.0. Box 276, I-39100 Bolzano (BZ), Italy.

Tel. +390471 017181 - Fax: +390471 017009 .

E-mail: marco.bietresato@unibz.it

Keywords: articulated tractor; tractor stability; safety index; self-locking articulation, Matlab ${ }^{\circledast}$ simulation.

Acknowledgments: the authors wish to thanks eng. Pietro Afier for his help in the implementation of the simulator.

Conflict of interests: the authors declare no potential conflict of interests.

Conference presentation: this paper has been submitted to The Italian Society of Agricultural Engineering for the $10^{\text {th }}$ AIIA Conference "AIIA13 Horizons in agricultural, forestry and biosystems engineering", which will be held in Viterbo, University of Tuscia, Italy, on September 8-12, 2013.

(C) Copyright F. Mazzetto et al., 2013

Licensee PAGEPress, Italy

Journal of Agricultural Engineering 2013; XLIV(s2):e133

doi:10.4081/jae.2013.s2.e133

This article is distributed under the terms of the Creative Commons Attribution Noncommercial License (by-nc 3.0) which permits any noncommercial use, distribution, and reproduction in any medium, provided the original author(s) and source are credited.
Thanks to the low centre-of-gravity, the resulting rollover angle with the vehicle in straight configuration is promising $\left(43.8^{\circ} \rightarrow 96 \%\right)$ : it is greater than the maximum lateral $\left(20^{\circ} \rightarrow 36 \%\right)$ and frontal $\left(38^{\circ} \rightarrow 78 \%\right)$ slope angle ever recorded on terraced vineyards. The same rollover angle is lower when the tractor turns.

\section{Introduction}

\section{General considerations and problem description}

Most of the vineyards assigned to the production of high-quality grapes and wines are very problematic by the point of view of the mechanisation. In fact, these vineyards are often placed in steep hillsides and use traditional training systems (such as "pergola"), considered by farmers essential for obtaining a better maturation of grapes and a full development of the aromas which will characterize the wines obtained from those grapes. The only possible mechanization in these difficult environments makes use of small tracked or wheeled tractors capable of operating in: i) very narrow inter-rows, often lower than $1.00 \mathrm{~m}$ and with the risk of roll-over, ii) reduced spans under the arbours (commonly $\leq 1.80 \mathrm{~m}$, often $\leq 1.60 \mathrm{~m}$ ); iii) steep and very tight curves in row heads, with great difficulties of manoeuvre.

In particular, the tractor resulting from these design requirements and proposed in this work has small dimensions, necessary to operate in this environment, and presents 4 -wheel drive together with a central articulation having two rotational degrees-of-freedom (dof). This joint allows a great manoeuvrability on the horizontal plane and the overcoming of the soil harshness. The described features are surely strong design points but could be potentially critical for the stability of the vehicle since affecting the baseline dimensions and shape. Therefore, a mathematical description of vehicle-ground interactions has been implemented.

The study of the dynamic behaviour of agricultural tractors and of offroad vehicles in general, is a very actual research topic, since it allows having a greater awareness of how design choices influence the stability, the handling and the operational limits of a vehicle, and hence the safety level of the occupants (Guarnieri \& Fabbri, 2002).

One of the most interesting topics in studying the stability rollover of agricultural tractors operating on steep hillsides is the capability for the analyst to predict, prevent or limit the damage caused by a possible overturning. These situations can be described through analytical equations relating the vehicle attitude to the incipient overturning condition. This problem can be addressed in two different ways: (i) energetic or (ii) Newtonian.

In (Guzzomi, Rondelli, Guarnieri, Molari, \& Molari, 2009), for example, the energetic approach allowed to analyse the different initial rollover conditions of tractors and to evaluate the energy available at rollover start. Thanks to this study it has been possible to realize that the available energy may not be a linear function of tractor mass, as assumed by the international testing procedure, and to define the application range of the energy formula used in Code 6 (OECD, 1990). 


\section{State of the art}

Most of the works, however, use a Newtonian approach and some of them can consider also a three-dimensional tire-terrain interaction model (Pazooki, Rakheja, \& Cao, 2012) or the effects of the rear track width and of an additional weight placed on the wheels on the stability of a tractor when driving on side slopes (Gravalos et al., 2011). Eventual trailers or agricultural implements attached to the tractor change substantially the behaviour of the whole vehicle and could easily lead it to critical conditions, thus they deserve deeper investigations. For example, in (Ji-hua, Jin-liang, \& Yan, 2011) a linear dynamics model of tractor/full trailer with six dofs is presented and used to evidence critical situations occurring when avoiding an obstacle (rearward amplification phenomenon).

The model of the lateral dynamics of a tractor with a single-axle grain cart was studied in (Karkee \& Steward, 2010); a sensitivity analysis allowed to identify the effect of uncertainty/variation of some parameters on system responses. In (Popescu \& Sutru, 2009) the longitudinal stability of the tractor-front-end loader system and of tractorforklift system was studied in the most difficult work situations: braking and moving the load on the forks while descending on a slope. The same analytical approach is used also in (Guzzomi, 2012) where a geometrical model for predicting the rollover initiation angle of traditional farm tractors fitted with front-axle pivot under quasi-static conditions is presented. The model uses a kineto-static approach based on two rigid bodies: the front axle and wheels (anterior body), and the remaining machine and the rear wheels (posterior body). Conventional tractors have been studied also in (Ahmadi, 2011) through a dynamic model capable of investigating the effects of forward speed, ground slope and wheel-ground friction coefficient on lateral stability at the presence of position disturbances.

The present work uses an approach similar to (Coombes, 1968; Guzzomi, 2012; Scarlett et al., 2006) but deals with articulated farm tractors, i.e. wheeled tractors having a central joint used for steering (Mazzetto, Gallo, Vidoni, Bisaglia, \& Calcante, 2012; Mazzetto, Gallo, Vidoni, \& Bisaglia, 2012). The rollover angle is calculated in a quasistatic condition and the attitude of the tractor in every slope condition is quantified by a stability index, in a way similar to (Yisa, Terao, Noguchi, \& Kubota, 1998) and (Liu \& Ayers, 1999). This index synthetizes possible overturn conditions (e.g., roll and pitch angles) in a single number and it could be very useful if used as input signal for many real-time active safety devices acting on several systems, e.g.: braking systems, limited-slip differentials (Huang, Zhan, \& Wu, 2012), variable-geometry roll-over structures (Silleli et al., 2007), self-levelling cab system (Mashadi \& Nasrolahi, 2009).

\section{Aim of the research}

The aim of this work was to investigate numerically the stability of narrow-track wheeled articulated farm tractors and to evaluate the possibility of introducing a real-time safety device acting on the central joint. The article presents a properly-developed mathematical model, used to simulate the operation of this type of tractors.

\section{Materials and Methods}

\section{Central joint design and analysis}

A central joint with two dofs was initially selected to be installed on the articulated tractor. This joint allows the steering of the vehicle (first dof) and, similarly to conventional tractors with front axle pivot, a simultaneous inclination in the transverse plane when, for instance, a wheel encounters ground harshness (second dof). If a static, no slipping wheels condition is considered, the kinematics of lateral overturning of an articulated tractor with a 2-dof joint is similar to the case of conventional tractors (Coombes, 1968; Scarlett et al., 2006), with the only difference that the rollover starts from a single half of the vehicle (the upstream part; Figure 1) and not involves the whole vehicle as for conventional tractors (Figure 2). In particular, the axis of rotation of the overturning part of the articulated tractor would pass by the joint and by the contact point of the lowest wheel of the unstable part (Figure 1). If the downstream half is stable while the upstream part not, the joint position can be thought as fixed.

With the vehicle longitudinal axis perpendicular to the maximum slope direction (advancement along a c ontour line) the angle of incipient overturning (stability critical angle) for this triangular configuration of the supports is (Coombes, 1968; Guzzomi, 2012; Scarlett et al., 2006):

$$
\vartheta_{\sigma r}=\operatorname{arctg}\left[\frac{w_{b}\left(i-s_{1}\right)}{2\left(h_{b} s-h_{1} s_{1}\right)}\right]
$$

where $\mathrm{w}_{\mathrm{b}}, \mathrm{s}, \mathrm{s}_{1}, \mathrm{~h}_{\mathrm{b}}$ and $\mathrm{h}_{1}$ are defined as in Figure 1 and 2 . Since this articulated tractor is thought to be primarily used on slopes, the stability characteristics were enhanced by blocking the second dof of the joint central in conditions of possible rollover. By doing so, the polygon of stability changes from the triangle described above to a quadrilateral which joins all the wheel-ground contact points (Figure 3). That dof will instead remain in the normal operation of the tractor: this increases the comfort of the operator and makes all the wheels touch the ground.

\section{Kinematic models}

In order to evaluate the stability and the behaviour of an articulated farm tractor in different working and slope conditions, a simplified model has been developed. The vehicle-system has been evaluated in its main geometrical and mechanical parameters, Figure 4A and Table 1 , and the steering articulation has been considered as a revolute kinematic pair. For the reasons previously explained, in this work no pivot on the front ax is or independent suspensions have been considered, thus allowing to consider the tractor footprint given by the four wheels in contact with the surface. The revolute joint, that is in charge to simulate the steering system, is the active joint of the tractor and it is limited by the maximum steering angle, $\max \theta$. Moreover, a conventional configuration, i.e. with four wheels and rigid chassis syste $\mathrm{m}$ (without any front axle pivot), Figure 4B, has also been considered to allow a suitable stability comparison and evaluation.

As regards the steering, the overall model has been developed by means of the classical steering kinematics (Genta, 2000), thus neglecting the contributes of sliding and aerodynamic frictions. In such this way, it is possible to evaluate the position of the wheels in a steering c ondition, i.e. along a circle with different radius, fundamental elements for the stability evaluation.

\section{Quantification of the stability of a tractor}

The conventional agricultural tractor has been considered as a rigid central body with mass $\mathrm{m}$ and four possible contact points with the ground surface. The stability of a tractor can be classified at least into longitudinal (pitch) and lateral (roll) turning stability, both related to the tractor stability baseline, i.e. the polygonal line that connects all the wheels of the tractor as the wheels set on level ground. Generally speaking, the system is stable if the projection of the centre of gravity (COG) of the system on the travelled plane surface is inside the stabil- 
ity baseline. Thanks to this assumption, both the longitudinal and lateral stability can be defined.

In the case of the articulated tractor, the stability baseline can be defined in the same way as for the conventional one; the system COG has instead to be computed at each step/configuration since it is directly related to the steering angle. If the COG of the forward and backward parts are considered (COG_b, COG_f), the system COG can be computed.

As the tractor moves at reasonably low speed during its normal operations (lower than $1.5 \mathrm{~m} \mathrm{~s}^{-1}$ ), the dynamic stability can be treated with a quasi-static approach, i.e. the inertial terms can be considered negligible, without the risk of invalidating the results. This means that the only force to be considered is the weight $(F P)$, that is distributed on the four wheels (Figure 5A) in correspondence to the four ground-tractor points of contact.

The weight force is applied on the system COG, it is $F p=-m g z$, directed along the absolute vertical axis. Hence, with the aim of evaluating the stability of the system, it has been chosen to simulate the trac tor while travelling along a circumference with radius $r$ and in different slope conditions, i.e. turning on a plane with different values of the slope (referred to as $\alpha$ ).

Following the approach in (Liu \& Ayers, 1999), roll and pitch stability indexes have been defined and implemented. The generic (percentage) stability index $(S I)$ is:

$$
S I=\left(1-\frac{X}{X_{\text {cri }}}\right) \cdot 100
$$

where $X$ is the state variable for evaluating the stability and $\mathrm{X}_{\text {cri }}$ its critical value.

In order to compute the $S I$, the following procedure has been followed.

First of all the following data have been computed:

- $\quad$ current position of the four wheels;

- $\quad$ projection of the COG on the inclined plane ( $P$ in Figure 5B);

-position of the geometric centre of gravity $(G C O G)$ with respect to the absolute reference system;

- spatial definition of the tangential $\left(\mathrm{u}_{2}\right)$ and orthogonal $\left(\mathrm{u}_{1}\right)$ unit vectors with respect to the system path.

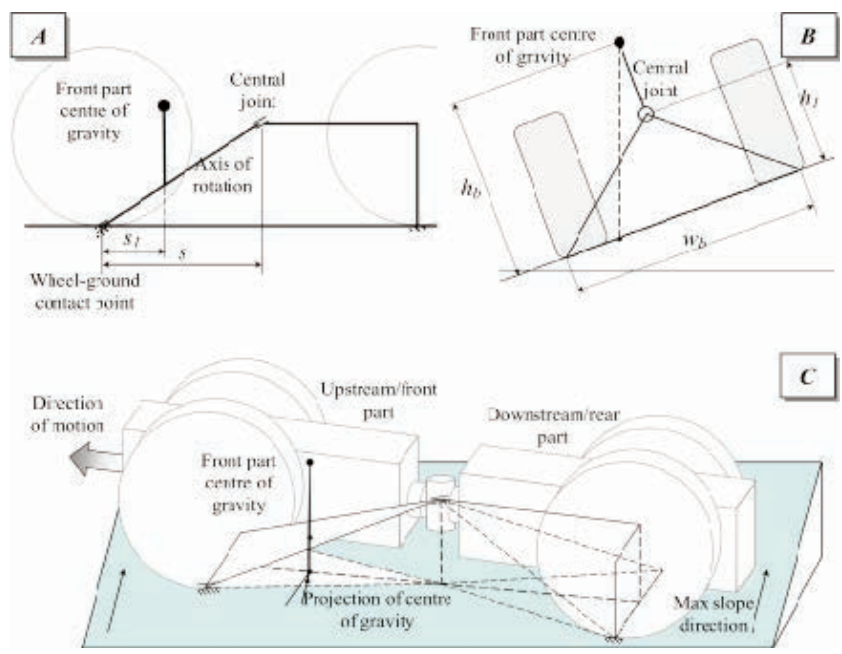

Figure 1. Side (A), front (B) and axonometric (C) views of the equivalent mechanism for an articulated tractor with a 2-dof central joint.
With this data available, the indexes are calculated by evaluating the distance of the projection of the tractor COG on the running plane to the symmetry line $(X)$, with respect to the zero stability condition $\left(X_{\text {cri }}\right)$, i.e. when the COG projection falls on the baseline border. In Figure 5B these distances are shown.

For the roll stability index, first of all the COG projection point $P$ is evaluated in its $\mathrm{u}_{1}$ coordinate to select the nearer stability baseline side, e.g. $\mathrm{BC}$ in the figure. After that, the line orthogonal to $\mathrm{BC}$ and to the point $S$, intersection between this line and the line defined by the unit vector $\mathrm{u}_{2}$, are computed. Thus, given $P\left(\mathrm{x}_{\mathrm{p}}, \mathrm{y}_{\mathrm{p}}\right)$ and $\mathrm{ax}+\mathrm{by}+\mathrm{c}=0$, i.e. the equation for $\mathrm{BC}$, the parameters $\mathrm{a}^{\prime}, \mathrm{b}^{\prime}$ and $\mathrm{c}^{\prime}$ of the orthogonal line become:

$$
\left\{\begin{array}{c}
a^{\prime}=b \\
b^{\prime}=-a \\
c^{\prime}=-b x_{p}+a y_{p}
\end{array}\right.
$$

while the coordinates of $S$ result:

$$
\left\{\begin{array}{c}
x_{s}=0 \\
y_{s}=-\frac{c^{\prime}}{b^{\prime}}
\end{array}\right.
$$

By computing the coefficients and the coordinates of $S$, it is possible to evaluate the SP and SQ distances, i.e. the $X$ and $X_{\text {cri }}$ for the roll stability index:

$S I_{\text {roll }}=\left(1-\frac{S P}{S Q}\right) \cdot 100$

The $\mathrm{SI}_{\text {pitch }}$ is defined and computed in a similar way.

\section{Simulations}

The kinematics of the tractors together with the computation of the COG and of the stability indexes have been implemented in a simulator developed in Matlab ${ }^{\circledR}$ (The Mathworks, Natick, Massachusetts, USA), to evaluate and compare the two different tractor architectures and to lay the basis for future safety applications.

In Table 2 the main parameters for the two architectures are reported. As can be appreciated, the total weight of the two tractors is the same, as well the maximum distance between the two wheelbases.

Figure 6 represents a visual output of the Matlab ${ }^{\circledR}$ simulator and shows the different positions of the stability baseline of the conventional tractor along a circular trajectory lying on a sloped plane. The $\varphi$ angle is the angular coordinate representing the current position of the vehicle along the circumference. The tractor travels anticlockwise along the circumference, starting from the point with maximum $x$ coordinate.
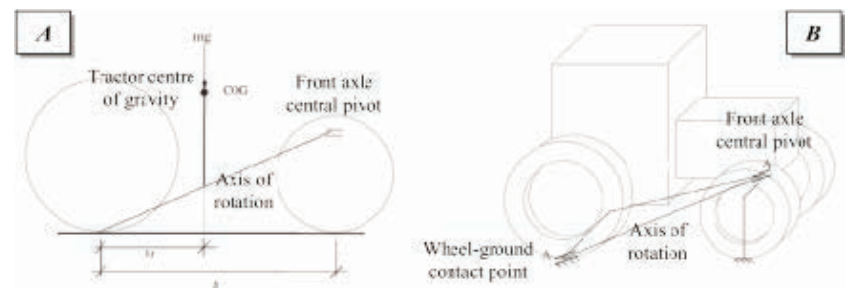

Figure 2. Side (A) and axonometric (B) views of the equivalent mechanism for a conventional tractor with a front axle central pivot (Coombes, 1968; Guzzomi, 2012; Scarlett et al., 2006). 
Table 1. Nomenclature.

\begin{tabular}{ll} 
wb_f & Forward wheelbase width \\
wb_b & Backward wheelbase width \\
\hline wb_b_d & Distance joint-backward wheelbase \\
wb_f_d & Distance joint-forward wheelbase \\
\hline p_b & Backward tread width \\
P_f & Forward tread width \\
\hline COG_b & Backward Centre Of Gravity position \\
COG_f & Forward Centre Of Gravity position \\
\hline COG & Centre Of Gravity
\end{tabular}

Table 2. Stalk length of industrial hemp varieties

\begin{tabular}{llll}
\multicolumn{3}{c}{ Conventional Tractor } & \multicolumn{2}{c}{ Articulated Tractor } \\
COG coordinates & {$[0,0.80,0.60] \mathrm{m}$} & COG coordinates (f and b) & {$[0,0,0.35] \mathrm{m}$} \\
L & $1.20 \mathrm{~m}$ & L (distance wbvs. joint) & $0.60 \mathrm{~m}$ \\
\hline wb_f & $0.60 \mathrm{~m}$ & wb_f & $0.70 \mathrm{~m}$ \\
wb_b & $0.80 \mathrm{~m}$ & wb_b & $0.70 \mathrm{~m}$ \\
\hline p_b & $0.20 \mathrm{~m}$ & p_b & $0.20 \mathrm{~m}$ \\
p_f & $0.26 \mathrm{~m}$ & p_f & $0.20 \mathrm{~m}$ \\
\hline Mass & $950 \mathrm{~kg}$ & mass (fw, bw) & $570,380 \mathrm{~kg}$
\end{tabular}

Table 3. Values of the $\mathrm{S}^{\mathrm{Iroll}}$ in the two most critical angular positions along the circumference (radius $\mathrm{r}=5 \mathrm{~m}$ )

\begin{tabular}{|c|c|c|c|c|c|c|}
\hline \multirow[b]{2}{*}{$\alpha$} & \multicolumn{3}{|c|}{$\varphi=90^{\circ}$} & \multicolumn{3}{|c|}{$\varphi=270^{\circ}$} \\
\hline & Conventional tr. & Articulated tr. & Absolute diff. & Conventional tr. & Articulated tr. & Absolute diff. \\
\hline $10^{\circ}$ & $83 \%$ & $89 \%$ & +6 & $79 \%$ & $83 \%$ & +4 \\
\hline $20^{\circ}$ & $62 \%$ & $74 \%$ & +12 & $59 \%$ & $67 \%$ & +8 \\
\hline $30^{\circ}$ & $39 \%$ & $57 \%$ & +18 & $34 \%$ & $51 \%$ & +17 \\
\hline $40^{\circ}$ & $11 \%$ & $36 \%$ & +25 & $6 \%$ & $30 \%$ & +24 \\
\hline
\end{tabular}

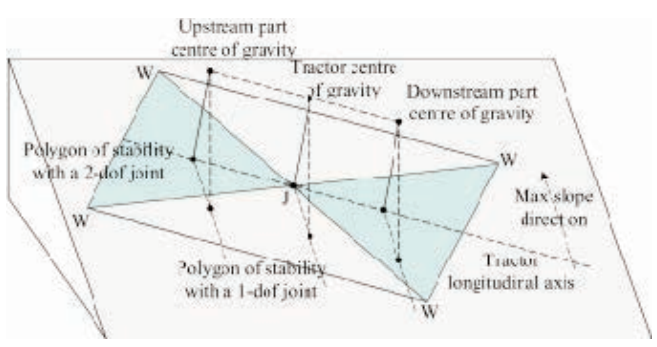

Figure 3. Generic situation of an articulated tractor moving uphill (W: wheel-ground contact point; J: central joint; light-blue triangles: stability polygons with a 2-dof joint); in the represented case, the upstream part would undergo to a lateral rollover (note the projection of the upstream centre of gravity) if the central joint had both the initial 2 dof; with a 1-dof joint the tractor is stable.

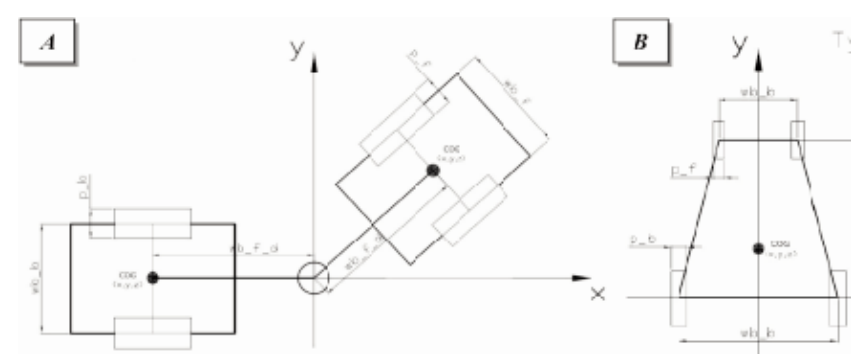

Figure 4. Tractor geometrical parameters (A: Articulated Tractor; B: Conventional Tractor).

\section{Experimental tests}

The experimental tests regarded the lateral rollover of the articulated tractor in two different configurations: (a) side overturning of vehicle with the two halves aligned, equivalent to a straight-ahead motion of the tractor along a contour line of a hillside, (b) side overturning of vehicle with the two halves angled, equivalent to a steering manoeuvre of the tractor going upstream from a contour line of a hillside.

When the vehicle was tested in an angled configuration, the longitudinal symmetry axis of the downstream portion of the vehicle passed through the centre of the footprint of a wheel of the other part (according to OECD prescriptions; Figure 7). This configuration corresponds to a steering angle of $30^{\circ}$ and a curvature radius of the trajectory of $2.4 \mathrm{~m}$.

\section{Results}

\section{Validation of the numerical model}

With a straight configuration, the experimental test recorded a limit of lateral stability of $43.8^{\circ}$ and the numerical model gave a critical angle of $45.7^{\circ}$. The difference between the limit angle measured experimentally and calculated by the simulator $(+4 \%)$ can be reasonably ascribed to the deformation of the tyres, not accounted in the numerical model presented here. If the deflection of the tyres were taken into account, the lateral inclination of the vehicle would be greater than the slope of the ground and, therefore, the inclination limit would be lower. The angular misalignment found $\left(\varnothing \alpha=1.9^{\circ}\right)$, in fact, corresponds to $2.3 \mathrm{~cm}$ if reported on the baseline width of the tractor using the following formula: . This length can be interpreted as the value of deflection undergone by the two tyres of the downstream side and it is compatible with the reduced pressure they had in the tests (1.6 bar, i.e. the value prescribed by OECD protocols). In the same (OECD) angled configuration, the experimental test recorded a limit of stability of $41.1^{\circ}$ and the numerical model gave a critical angle 


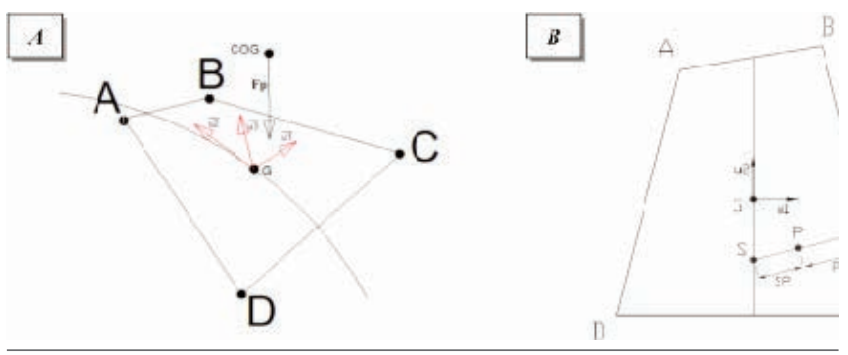

Figure 5. Tractor: $A)$ baseline $(\mathrm{ABCD})$ and weight force; $B)$ stability index computation.

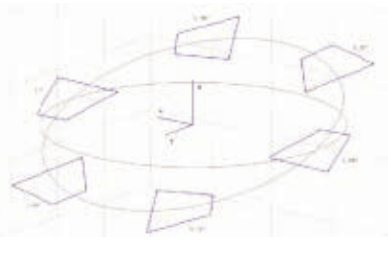

Figure 6. Simulator visual output.

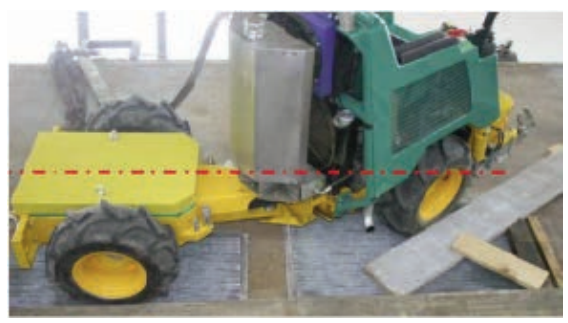

Figure 7. Experimental test of lateral stability with the tractor in an angled configuration.

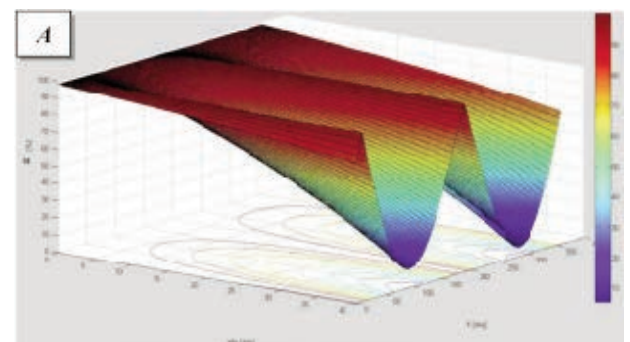

of $41.5^{\circ}$, hence only $+1 \%$ than the experimental result. In this case the predictive capabilities of the model are even better than the previous case. Indeed, this configuration is more critical from the stability point of view and the rollover is reached more easily, preventing an excessive load on the tyres sides and hence without an excessive deflection.

\section{Stability evaluations through the numerical model}

The simulations have been carried out for different circle radii and slopes. For example, Figure 8 and Figure 9 show the $\mathrm{SI}_{\text {roll }}$ for the two tractors when describing a circle radius of $5 \mathrm{~m}$, i.e. the angle that spans the entire circumference, and for slope values ranging from $0^{\circ}$ to $40^{\circ}$. Looking at the results (Table 3 ), it can be easily appreciated how, in a quasi-static configuration, the roll stability index for an articulated tractor has better values than a conventional tractor.

Moreover, the adopted approach allows a fast assessment of the system stability and, if proper inertial measurement devices are installed on a tractor, it can be directly exploited for (i) a real-time computation of the system stability degree and (ii) the control and actuation of some active safety devices.

\section{Conclusions and future work}

In this work, the stability and human safety of narrow-track wheeled articulated tractors have been evaluated both numerically and experimentally.

First of all, considerations about the central joint and its role in a possible lateral rollover led to identify the opportunity of using a realtime safety device acting on it. This device would act only in case of incipient rollover by blocking the possibility of a part to rotate with

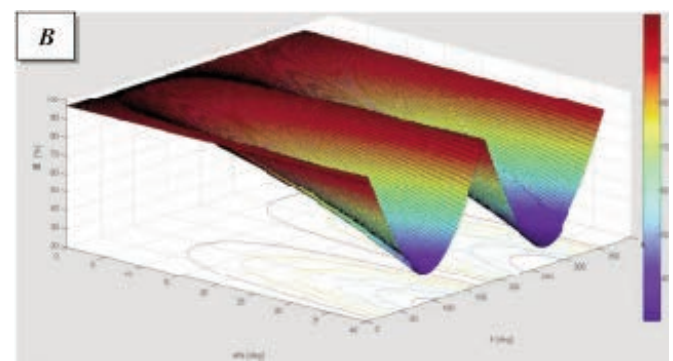

Figure 8. Roll stability index as a function of the slope and the tractor's position on the circumference. A) Conventional Tractor; B) Articulated Tractor.
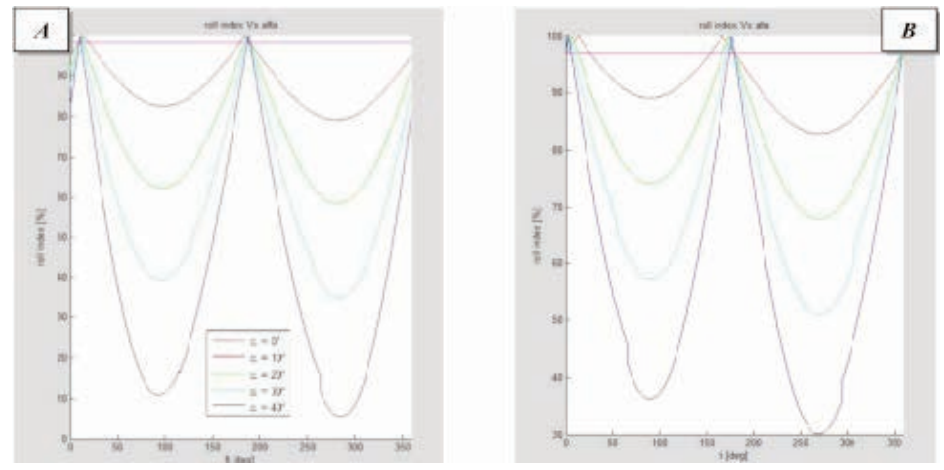

Figure 9. Roll stability index for different slope values. A) Conventional Tractor; B) Articulated Tractor. 
respect to the other on a transversal plane. During normal operations this dof is present and allows the tractor overcoming possible ground harshness, hence granting the full adherence of the tyres and the comfort of the operator.

After that, a kinematic model of the articulated tractor was developed using a quasi-static approach and then it was validated with the experimental results of some OECD overturning tests. The numerical results showed a good agreement with the experiments (differences of static results due only to having neglected the tyres' deflection, however within 4\%). Subsequently, the simulator was used to study and compare the dynamics of both articulated and conventional tractors. Then, a stability index both for the roll and pitch axis has been defined and the overall algorithm implemented in a Matlab ${ }^{\circledR}$ simulator.

The results show the goodness of the articulated architecture for tractors operating on hillsides ( $\mathrm{S}^{\text {Iroll }}$ greater than up to 25 percentage points) and encourage the exploitation, in a future work, of this simplified model for its implementation in real-time safety control systems related to the vehicle stability.

Future activities will cover the completion of the stability index to take also into account the dynamic phenomena, e.g. occurring when travelling on sharp harshness or when transporting fluids in a tank connected to the tractor (i.e., the equipment used for pesticide treatments). Moreover, the model will serve as a base for studying an innovative test platform for real vehicles. The dimension of this platform will allow a tractor to travel on it along a circular trajectory, as simulated in this work. Different road surfaces and obstacles will be used on the platform, to simulate real field conditions. A series of parameters related to the stability of the vehicle and to the operator's comfort will be detected during the movement of the tractor.

\section{References}

Ahmadi, I. (2011). Dynamics of tractor lateral overturn on slopes under the influence of position disturbances (model development). Journal of Terramechanics, 48(5), 339-346. doi:10.1016/j.jterra. 2011.07.001

Coombes, G. B. (1968). Slope stability of Tractors. In Farm Machine Design Engineering (pp. 18-33). Design Engineering Publications.

Genta, G. (2000). Meccanica dell'autoveicolo - Collana di Progettazione e Costruzione di Macchine (p. 568). Torino, Italy: Levrotto \& Bella.

Gravalos, I., Gialamas, T., Loutridis, S., Moshou, D., Kateris, D., Xyradakis, P., \& Tsiropoulos, Z. (2011). An experimental study on the impact of the rear track width on the stability of agricultural tractors using a test bench. Journal of Terramechanics, 48(4), 319323. doi:10.1016/j.jterra.2011.04.003

Guarnieri, A., \& Fabbri, A. (2002). Le ricerche sul comfort e sulla stabilità delle trattrici agricole [The research on the comfort and stability of agricultural tractors]. In Convegno Nazionale AIIA - La sicurezza delle macchine agricole e degli impianti agro-industriali (pp. 1-21). Alghero - Sassari, Italy: AIIA - Associazione Italiana di Ingegneria Agraria. Retrieved from http://www.aiia.info/Convegni ECongressi/2002/AIIA_2002-Alghero/RelazioniGenerali/relgenGuarnieri.pdf

Guzzomi, A. L. (2012). A revised kineto-static model for Phase I tractor rollover. Biosystems Engineering, 113(1), 65-75. doi:10.1016/j. biosystemseng.2012.06.007

Guzzomi, A. L., Rondelli, V., Guarnieri, A., Molari, G., \& Molari, P. G. (2009). Available energy during the rollover of narrow-track wheeled agricultural tractors. Biosystems Engineering, 104(3), 318-323. doi:10.1016/j.biosystemseng.2009.07.005
Huang, R., Zhan, J., \& Wu, J. (2012). Effect of Differential Modeling on Handling and Stability. In SAE-China and FISITA (Ed.), Proceedings of the FISITA 2012 World Automotive Congress (Vol. 198, pp. 441-448). Beijing, China. doi:10.1007/978-3-642-33795-6

Ji-hua, B., Jin-liang, L., \& Yan, Y. (2011). Lateral stability analysis of the tractor/full trailer combination vehicle. In 2011 International Conference on Electric Information and Control Engineering (pp. 2294-2298). IEEE. doi:10.1109/ICEICE.2011.5777033

Karkee, M., \& Steward, B. L. (2010). Local and global sensitivity analysis of a tractor and single axle grain cart dynamic system model. Biosystems Engineering, 106(4), 352-366. doi:10.1016/j.biosystemseng.2010.04.006

Liu, J., \& Ayers, P. D. (1999). Control Strategies and System for Tractor Protective Structure Deployment. In 1999 Summer Conference of the NATIONAL INSTITUTE FOR FARM SAFETY (p. Paper No. 9911). Ocean City, Maryland, USA. Retrieved from http://lamar.colostate.edu/ jhliu/project/NIFS_99.pdf

Mashadi, B., \& Nasrolahi, H. (2009). Automatic control of a modified tractor to work on steep side slopes. Journal of Terramechanics, 46(6), 299-311. doi:10.1016/j.jterra.2009.08.006

Mazzetto, F., Gallo, R., Vidoni, R., \& Bisaglia, C. (2012). Development and characterization tests of a small hydraulic-powered tractor prototype for use in extreme sloped vineyards. In International Conference of Agricultural Engineering CIGR-Ageng. Valencia, Spain. Retrieved from http://www.ageng2012.org- www.ageng 2012.org/images/fotosg/tabla_137_C2129.pdf

Mazzetto, F., Gallo, R., Vidoni, R., Bisaglia, C., \& Calcante, A. (2012). Designing and testing a new small tractor prototype for the mechanisation of terraced-vineyard farming systems in South-Tyrol. In A. Conti, S. Failla, \& D. Camillieri (Eds.), International Conference RAGUSA SHWA 2012 - "Safety Health and Welfare in Agriculture and in Agro-food Systems" (pp. 243-250). Ragusa, Italy: Elle Due. Retrieved from http://www.ragusashwa.it/CD_2012/lavori/TOPIC5/ orale/topic 5_243_250.pdf

OECD. (1990). Code 6 - OECD Standard Code for the Official Testing of Front Mounted Rollover Protective Structures on Narrow Track Wheeled Agricultural and Forestry Tractors. Paris, France: Organisation for the Economic Co-operation and Development.

Pazooki, A., Rakheja, S., \& Cao, D. (2012). Modeling and validation of off-road vehicle ride dynamics. Mechanical Systems and Signal Processing, 28, 679-695. doi:10.1016/j.ymssp.2011.11.006

Popescu, S., \& Sutru, N. (2009). Contributions to the study of the dynamics of agricultural tractors equipped with front-end loader and rear forklift loader. In Engineering for Rural Development International Scientific Con (pp. 165-170). Jelgava, Latvia. Retrieved from http://www.cabdirect.org/abstracts/20093261569. html

Scarlett, A. J., Reed, J. N., Semple, D. A., Seward, P. C., Stockton, A. D., \& Price, J. S. (2006). Operator roll-over protection on small vehicles - Research Report 432 (p. 84).

Silsoe, United Kingdom. Retrieved from http://scholar.google.com/ scholar?hl=en\&btnG=Search\&q=intitle:Operator+roll-over+protection+on+small+vehicles\#0

Silleli, H., Dayığlu, M. a., Gültekin, A., Ekmekçi, K., Yıldız, M. a., Akay, E., \& Saranlı, G. (2007). Anchor mechanism to increase the operator clearance zone on narrow-track wheeled agricultural tractors: Prototype and first tests. Biosystems Engineering, 97(2), 153-161. doi:10.1016/j.biosystemseng.2007.02.016

Yisa, M. G., Terao, H., Noguchi, N., \& Kubota, M. (1998). Stability criteria for tractor-implement operation on slopes. Journal of Terramechanics, 35(1), 1-19. doi:10.1016/S0022-4898(98)00008-1 